\title{
EFFECTS OF BLINDFOLD AND TAIL BEND OF EGYPTIAN WATER BUFFALO ON BEHAVIOURAL REACTIVITY AND PHYSIOLOGICAL RESPONSES TO PAIN INDUCTION
}

\author{
Rady A. Mohamed*, Usama A. Abou-Ismail**, Mustafa Shukry***, Ahmed M. \\ EImoslemany*, Mohamed Abd-Elmaged $* * * *$
}

\author{
*Department of Hygiene and Preventive Medicine, Faculty of Veterinary Medicine, Kafr El-Sheikh University, \\ Kafr El-Sheikh, Egypt. \\ ** Department of Husbandry and Development of Animal Wealth, Faculty of Veterinary Medicine, Mansoura University, \\ Gomhoria St., Mansoura, P.O. box 35516, Egypt. \\ *** Department of Physiology, Faculty of Veterinary Medicine, Kafr El-Sheikh University, Kafr El-Sheikh, Egypt. \\ ****Department of Animal Medicine, Faculty of Veterinary Medicine, Kafr El-Sheikh University, Kafr El-Sheikh, Egypt.
}

\begin{abstract}
Buffaloes are an important economic source for milk and meat production and for work and draught power in Egypt. Improving management practices applied to water buffalo may not only improve their welfare but has also an economic benefit. This experiment was carried out to determine the effect of blindfold and tail bending during restraint for veterinary treatment of Egyptian buffaloes on their behavioural reactivity and physiological responses to stress. Forty-eight Egyptian water buffalo bulls, naïve to the testing situation, were arbitrarily assigned to either blindfold (visual restriction) (BF), tail bending (physical control) (TT) or control (CT) (no visual restriction or physical control) treatment during restraint. Animals were entered the squeeze chute and the sides of the chute were adjusted to make contact with the animal body so that preventing unsteady movements, and were subjected to a 3day (day 1, 2 and 3) testing trials (injection stress) of three minutes each (1 $\mathrm{m}$ pre injection induction phase, $1 \mathrm{~m}$ injection induction phase and $1 \mathrm{~m}$ post injection induction phase). Heart rate (HR) was recorded using a stethoscope as soon as the animal was positioned in the squeeze chute and the respiratory rate (RR) was determined through counting the movement of flank region, and various reactivity-indicating behaviours were collected onto check sheet. Average HR decreased in both TT and $B F$ bulls during and after stress $(P=0.001)$ but the reduction in HR was greater in BF bulls $(67.25 \pm 3.41$ and 55.00 1.08 , respectively) in day 3 after stress $(P=0.001)$. Similarly, average RR decreased in both $T T$ and $B F$ bulls $(P=0.001)$ during and after stress but the reduction was greater in BF bulls during stress (25.38 \pm 0.53 and $19.92 \pm 0.33$, respectively). Blindfolding and tail bending buffalo bulls decreased average frequency of their behavioural indicators of reactivity including: chest chute forcing prestress $(P=0.01)$, during and post stress $(P=0.001)$; head move $(P=0.001)$; kicking prestress $(P=0.05)$ during stress $(P=0.001)$ and post stress $(P=0.05)$; struggling move prestress, during stress $(P=0.001)$ and post stress $(P=0.05)$. The reduction was greater in $B F$ bulls in case of chest chute prestress $(0.08 \pm 0.05$ and $0.50 \pm 0.16$, respectively), struggling move during $(0.33 \pm 0.02$ and $0.75 \pm 0.04$, respectively) and post stress $(0.13 \pm 0.06$ and $0.29 \pm 0.08$, respectively). Taken together, both tail bend and blindfold water buffaloes decreased behavioural and physiological indicators of stress but BF appeared more beneficial and may therefore be recommended to reduce stress accompanying routine veterinary examination of buffaloes.
\end{abstract}

Key words: Buffalo, Blindfold, Reactivity, Restraint, Tail bend, Welfare.

\section{INTRODUCTION}

With a population of more than 4 million animals in Egypt, buffaloes are considered an important economic source for milk and meat production and for work and draught power
(FAO, 2011). Egyptian buffaloes are well adapted to the subtropical environmental conditions and account for $66 \%$ of the total national production of milk and $45 \%$ of the meat (Borghese, 2010). Egyptian buffalo comes on the $4^{\text {th }}$ place worldwide- after India, Pakistan and China- in milk production 
(2,300,000 tons of milk) (FAO, 2011), and under good management their milk production ranges between 1000 and $3000 \mathrm{~kg}$ per lactation season, two to three times higher than that of native cows.

However, despite the large size of the Egyptian population of buffalo research has not focused on improving management and husbandry practices applied to them as much as in cattle. Improper handling of animals can injure the animal itself, the animal handler and, most importantly, the man-animal relationship. Improper handling may have also an economic impact represented in reducing carcass quality and in the costs of treatment of animal and carcass damage. Therefore, proper handling of animals may not only improve human safety and animal welfare but can also have an economic impact. In addition, improving animal welfare can also result in an increase in the accuracy of experimental results that are less confounded by handling stress, and in a reduction in the number of animals used. The capacity of an individual animal to cope with environmental challenges and aversive situations is an important part of its welfare (Broom, 1988; Kilgour et al., 2006).

In modern dairy production, buffaloes are kept loose in complex environments and exposed to potentially stressful challenges such as handling and physical restraint. Some management practices applied to large dairy animals require handling, restraint and giving them injection in squeeze chutes such as routine veterinary examination and treatment, vaccination, branding, bleeding and minor surgical operations. Management practices that compromise the welfare of livestock may alter plasma hormone concentrations, induce behavioural modifications, and impair immune function (Broom and Johnson, 1993; Chirase et al., 2001; Johnsen et al., 2001). Behavioural and physiological responses have been proposed as indicators of the animal's capacity to cope with adverse effects of environment and can therefore be used as indexes of stress.

Numerous studies have assessed the effect on animal welfare of handling and restraint. It has been shown that handling and restraint can increase the heart rate, respiratory rate and plasma cortisol concentrations of cattle to levels comparable to those recorded during transport and slaughter (Lay et al., 1992; Zavy et al., 1992; Mitchell et al., 2004; Solano et al., 2004; Herskin et al., 2007; Szenci et al., 2011, Stewart et al., 2013). Baszczak et al. (2006), Ewbank, (1961), Grignard et al. (2001), Mitchell et al. (2004) and Müller et al. (2008) demonstrated that the majority of cattle restrained and given injections in a head gate became highly agitated and most struggled to withdraw their head or lunged forward when stimuli were applied to the neck. Similarly, Pilz et al. (2014) declared that cleaning of the perivaginal region and vaginal examination, that involved physical handling, touching and examination of animals, has been shown to increase avoidance reactions and heart rates in the treated animals. Attempts to escape and physical contact with the head gate can result in pain and injury, including bruising to the neck and back region (Grandin, 1998). Not only does increased carcass bruising represent an economic loss, but it may also be an indicator of compromised animal welfare (Jarvis et al., 1996).

An extensive amount of research work has also addressed the effect of other of management stressors on animal welfare, such as handling (Boissy and Bouissou, 1988; Jezierski et al., 1999), stroking (Schmied et al., 2008), branding (Lay et al., 1992; 
Schwartzkopf-Genswein et al., 1997, 1998), loading and noise (Agnes et al., 1990; Van De Water et al., 2003), space restriction (Maton and Daelemans, 1989; Fisher et al., 1997), restriction of movement and isolation (Le Neindre, 1993; Herskin et al., 2007), and shipping (Kegley et al., 1997; Phillips and Santurtun, 2013; Genther and Hansen, 2014). However, very little is known about the effect of stress of routine veterinary examination and restraint on behaviour, performance and welfare of buffaloes (Hussein et al., 1997; Kanchev et al., 1997). Moreover, cattle rearing techniques are often used for buffaloes, even though those techniques may not be appropriate for buffaloes.

Handling and restraint of Egyptian buffaloes appears to be more difficult compared to handling and restraint of native cows. This could be referred to the fact that buffaloes are bigger in size than cattle, and that nearly all buffaloes are horned animals. However, it could also be due to the increased reactivity of the buffaloes to environmental stressors than cattle because they are less tame than cows i.e. they were domesticated at later time (5000 years) compared to cows $(10,000$ years) (Cockrill, 1974). Therefore, management practices that could decrease reactivity of buffaloes during handling and restraint may not only help facilitate handling these animals but can also improve their welfare.

Blindfold has traditionally been used by ancient Egyptians to reduce reactivity of the animals therefore facilitating the process of handling and manipulation (Shahin, 2004). The use of blindfold as a method of reducing reactivity and improving welfare of cattle by reducing levels of fear through elimination of the human proximity and handler visibility has been recommended (Fowler, 1995; Ewbank, 2000; Mitchell et al., 2004; Müller et al., 2008). However, methods other than blindfolding may be required under different conditions to restrain animals e.g. in fields where animals may require immediate treatment and handling but the use of blindfold or the restraint chute is not feasible. There is therefore the possibility of using physical method of restraint such as tail bending. However, the use of these methods in buffalo lacks the scientific evidence regarding their effect on welfare of these animals. Moreover, data on Egyptian buffalo are lacking to a scientific comparative studies on the effects of blindfold and tail bending on short-term behavioural and physiological measures of welfare.

The objective of the current study was to examine the potential calming effect of blindfold and tail bend on Egyptian water buffalo during restraint for routine veterinary examination. A further aim of the study was to compare between the effects of blindfold and tail bend on the reactivity of buffaloes during restraint and pain induction.

\section{MATERIALS AND METHODS}

\section{Animals:}

This study was carried out in a private farm, belonging to El-Gharbia Governorate, Egypt. Ninety-six Egyptian water buffalo bulls with an average body weight of $234.5 \mathrm{~kg}$ and an average age of 15-18 months were arbitrarily selected and used in this study. The herd was formed about 1 year before the experiment and has been handled regularly in a loose housing (free animals) system. All tested 
animals came from a single herd to reduce the potential confounding effect of previous experience.

\section{Management:}

Bulls were housed in large yards $(12 \mathrm{~m}$ width $\times 20 \mathrm{~m}$ length). Two thirds of the yard were covered with a shed and the remaining third was left uncovered. Bulls were allowed ad libitum access to green fodder (Trifolium Alexandrium), straw and fresh drinking water. A concentrate mixture was provided at a rate of $6 \mathrm{~kg} / \mathrm{bull} / \mathrm{day}$, and was divided on two meals i.e. a meal in the morning (6 am) and a second meal in the evening (6 pm).

\section{Experimental treatments:}

All animals were acclimated to an ordinary squeeze chute with head gate for three days prior to the start of the experiment. Animals were tested daily on three consecutive days at nearly the same time each day. Each subject animal received the same treatment each day. Buffalo bulls were moved from their yards singly and were run through a straight 3 $\mathrm{m}$ hay rack raceway to the testing facility site. To control for the possible effect of the time of the day or the effect of communication between individual bulls being tested and those waiting in the yard, the order of testing was preassigned and counter balanced between treatments. Only one bull was inside the testing facility at a time, and the remaining animals were kept in the yard.

During restraint, the sides of the chute were adjusted to make contact with the animal body so that preventing unsteady movements, but bulls were not squeezed. Once the bull was restrained in the squeeze chute, two experimenters positioned themselves one on either side of the animal approximately $2 \mathrm{~m}$ away from the animal and they remained silent and still until the data collection was finished. The experiment was conducted between 0800 and $1200 \mathrm{~h}$ on each of the three experimental days. Bulls were lightly restrained in the squeeze chute for three minutes $(1 \mathrm{~m}$ pre stress induction phase, $1 \mathrm{~m}$ stress induction phase and $1 \mathrm{~m}$ post stress induction phase) and during each phase (one-minute duration) different measures of the study (see later) were collected. All stock men, including those who injected the animals, operated the squeeze chute, and handled the bulls during the experiment remained the same and maintained the same positions and conditions throughout the time of the experiment.

During the stress induction phase three injections were given to the animal with twenty seconds interval. In each single injection the individual animal was injected with $6 \mathrm{ml}$ of sterile saline solution (sodium chloride $0.9 \%$, Al-Mottahedoon Pharma Company, $10^{\text {th }}$ of Ramadan City, Egypt) subcutaneously in the side of the neck region. The reason why the animal was injected three times was to simulate what may commonly happen during the routine veterinary check where animals may be vaccinated with more than one vaccine that cannot be mixed. The volume of the medication may sometimes be large thus necessitating dividing them into two or more injections. It is also the case that some medications may interact together so they should be administered in separate injections. Each individual bull thus remained in the chute for three minutes testing duration before it was released.

Animals were arbitrarily allocated to one of the following three experimental treatments. 
1- Control treatment (CT): Bulls were entered into the squeeze chute and the sides of the chute were adjusted to the sides of the animal body before the procedures of stress induction were applied.

2- Tail bend treatment (TT): Bulls were entered into the squeeze chute and the sides of the chute were adjusted to the sides of the animal body and then the tail bending was done. The tail of the bull was held firmly close to the tail head (origin) and was then bent upward and forward before the procedures of stress induction were applied.

3- Blindfold treatment (BF): Bulls were entered into the squeeze chute and the sides of the chute were adjusted to the sides of the animal body and then blindfold was applied before the procedures of stress induction were applied. The blindfolding procedures were carried out according to Mitchell et al. (2004).

\section{Data collection:}

\subsection{Behavioural observation:}

Behaviour patterns recorded in this study were collected during each of the 3 minutes test period (pre, during and post stress induction). Behavioural patterns included vocalization, chest chute forcing (leaning against the front side of the chute with the chest or forequarters), head move (moving head at any direction), struggling move (lifting any leg off the ground or moving it violently), kicking (kicking the gate of the chute with the hind feet) and tail move (in case of BF and CT only). The researcher who scored the behaviour stood approximately 2 meters away from the chute.

\subsection{Heart and respiratory rate:}

Heart rate and respiratory rate were considered as an indicator of the physiological response of the animal to the experimental procedures. Heart rate was recorded (count/minute) using a stethoscope as soon as the animal was positioned in the squeeze chute and the respiratory rate was recorded (count $/ \mathrm{min}$ ) through counting the movement of flank region before, during and after stress induction.

\subsection{Ease of sorting test:}

It is the time taken by two experienced assistants from the assignment of the animal until it was entered the squeeze chute. This time was measured in seconds and was calculated using a stop watch.

\subsection{Flight time:}

The time taken by the bull from leaving the squeeze chute to reach the door of the pen was recorded as the flight time. This distance was 3 $\mathrm{m}$ and the time was measured using a stop watch. Immediately, after the end of the experiment, the individual bull was released from the chute where the bull could move down a race into its original yard. As there was no close proximity to other members of the herd to attract the individual animal immediately after the release this test represented the animal's response to the release from the chute.

\section{Statistical analyses:}

All statistical analyses were conducted using Stata version 13 (Stata Corp., College Station, TX). The association between treatments 
(control, tail bend, blindfold), day of testing (day1, day2, day3), and response order (pre, during and post stress) and various behavioural and physiological responses were evaluated using generalized estimating equations (GEE) with autoregressive correlation for repeated measures on animals. For RR, HR, ease of sorting and flight time, the model specification included normal distribution with identity link. The distributions of behavioural patterns responses (kicking, head move, chest-chute forcing, struggling move, and tail move) were strongly right skewed, with high percentage of zeros and could not be normalized by transformation, therefore, the frequency of each behaviour was modelled using GEE with Poisson distribution and a log link. For variance estimation, the Huber/White/sandwich estimator of variance was used and variables were considered significant at $\mathrm{P}<0.05$. Interactions between treatment and day of testing were reported for significant terms only. Separate models were fitted for pre-stress, during stress and post-stress responses. All results are presented as estimated marginal means (EMM) with $95 \%$ confidence intervals.

\section{RESULTS}

\section{Pre stress induction:}

Results showed that there was an effect of the experimental treatment on the frequency of chest chute forcing $(\mathrm{P}=0.005)$ with the animals in the $\mathrm{BF}$ treatment showing lower frequencies compared to animals in either TT or CT (see Figure 1). There was also an effect of the experimental treatment on the frequency of both head move $(\mathrm{P}=0.001)$ and kicking $(\mathrm{P}=0.05)$ with animals in $\mathrm{CT}$ displaying higher frequencies compared to those in either BF or TT (see Figure 2). There was however an experimental treatment*observation day effect on the frequency of struggling move $(\mathrm{P}=0.001)$ with animals in $\mathrm{CT}$ displaying higher frequencies than those in both BF and TT in the second and third observation day (see Figure 3).

Average duration of ease of sorting showed only an effect of the observation day $(\mathrm{P}=0.001)$ with animals in all experimental groups requiring lower ease of sorting time in the third observation day compared to the first observation day (see Figure 4).

Results showed that there was also an experimental treatment*observation day effect on the heart rate with animals in the CT $(\mathrm{P}=0.001)$ showing higher counts compared to those in either BF or TT in the second observation day, and those in the both $\mathrm{CT}$ and TT $(\mathrm{P}=0.001)$ showing higher counts than those in BF in the third observation day (see Figure 5).

\section{During stress induction:}

Average frequency chest chute forcing $(\mathrm{P}=0.001)$ and head move $(\mathrm{P}=0.001)$ showed an effect of experimental treatment with animals in CT displaying higher frequencies compared to their counterparts in both BF and TT (see Figure 6). Average frequency struggling move showed also an effect of experimental treatments $(\mathrm{P}=0.001)$ with animals in CT displaying higher values than those in either BF or TT, and those in TT displaying also higher frequencies compared to those in BF (see Figure 7). Similarly, average frequency tail move showed an effect of experimental treatment $(\mathrm{P}=0.001)$ with 
animals in CT displaying higher values compared to those in BF (see Figure 8). Average kicking frequency showed an experimental treatment*observation day effect $(\mathrm{P}=0.001)$ increasing in $\mathrm{CT}$ animals compared to their conspecifics in either BF or TT in both the second and third observation day (see Figure 9).

Average respiratory rate frequency showed an effect of experimental treatment $(\mathrm{P}=0.001)$ with animals in $\mathrm{BF}$ displaying lower counts than those in either TT or CT, and those in TT displaying lower counts relative to their counterparts in CT group (see Figure 10). There was however, an experimental treatment*observation day effect on the average heart rate frequency $(\mathrm{P}=0.001)$ with animals in both $\mathrm{BF}$ and $\mathrm{TT}$ displaying lower counts compared to those in the $\mathrm{CT}$ group in the first and second observation day, and those in the BF displaying lower counts relative to those in either TT or CT group in the third observation day (see Figure 11).

\section{Post stress induction:}

There was an effect to the experimental treatment on the frequency of both head move
$(\mathrm{P}=0.001)$ and struggling move $(\mathrm{P}=0.05)$ with bulls in both $\mathrm{BF}$ and TT displaying lower head move frequency compared to those in $\mathrm{CT}$, and those in $\mathrm{BF}$ displaying lower struggling move frequency relative to their conspecifics in either TT or CT group (see Figure 12).

There was also an effect to the experimental treatment on the respiratory rate frequency $(\mathrm{P}=0.001)$ with animals in $\mathrm{BF}$ having lower frequency compared to those in CT group (see Figure 13). However, average frequency heart rate showed an experimental treatment*observation day effect $(\mathrm{P}=0.001)$ with animals in both BF and TT having lower frequency relative to those in CT in the first and second observation day, and those in BF having lower frequency compared to those in either TT or CT in the third observation day (see Figure 14).

Results showed that there was an effect to the experimental treatment on the flight time duration $(\mathrm{P}=0.0001)$ with bulls of the $\mathrm{BF}$ showing longer flight time compared to those in both TT and CT, and those in TT showing longer flight time duration compared to those in CT group (see Figure 15). 


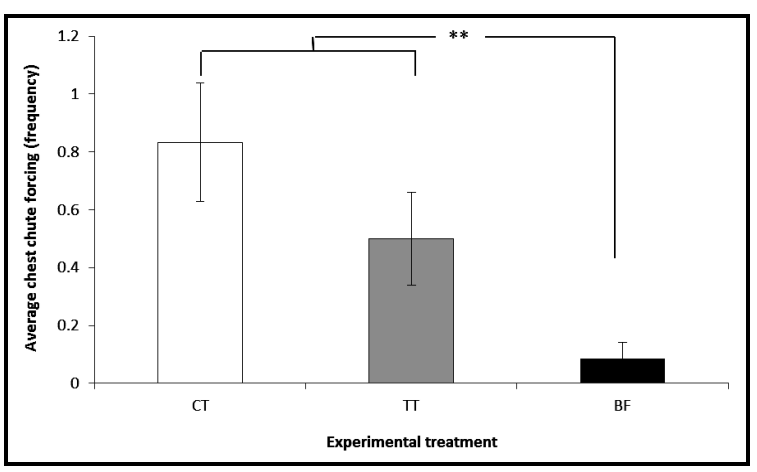

Figure 1: $\mathrm{EMM} \pm \mathrm{SE}$ 'average frequency chest chute forcing' by the bulls in the three experimental treatments pre stress induction. ${ }^{* *} \mathrm{P}<0.01$

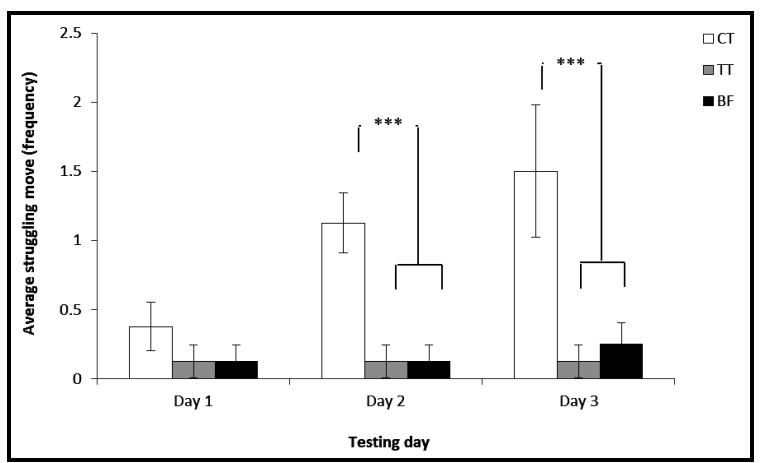

Figure 3: $\mathrm{EMM} \pm \mathrm{SE}$ 'average frequency struggling move' by the bulls in the three experimental treatments pre stress induction. $* * * \mathrm{P}<0.001$

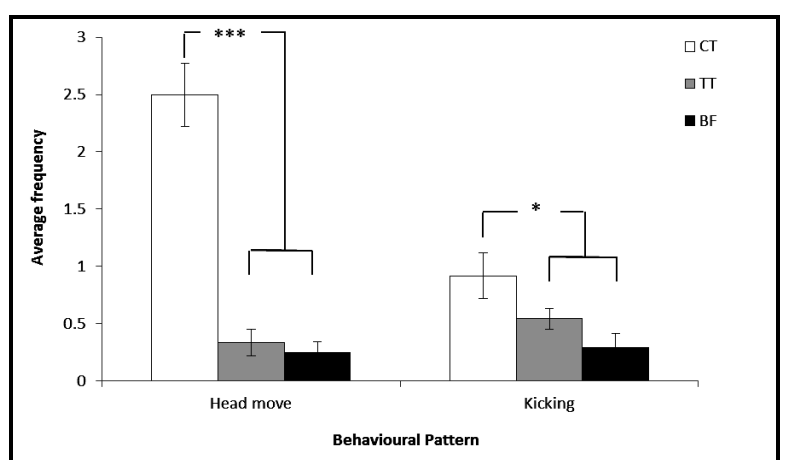

Figure 2: $\mathrm{EMM} \pm \mathrm{SE}$ 'average frequency head move and kicking' by the bulls in the three experimental treatments pre stress induction. $* \mathrm{P}<0.05, * * * \mathrm{P}<0.001$

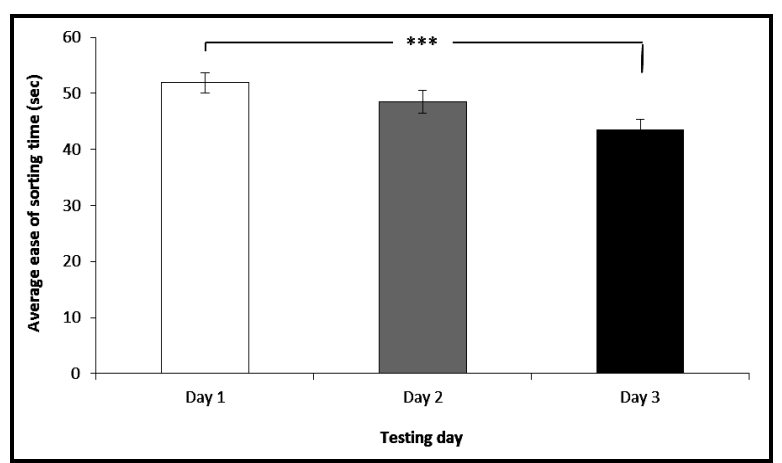

Figure 4: $\mathrm{EMM} \pm \mathrm{SE}$ 'average time ease of sorting' by the bulls in the three experimental treatments pre stress induction. ${ }^{* * *} \mathrm{P}<$ 0.001

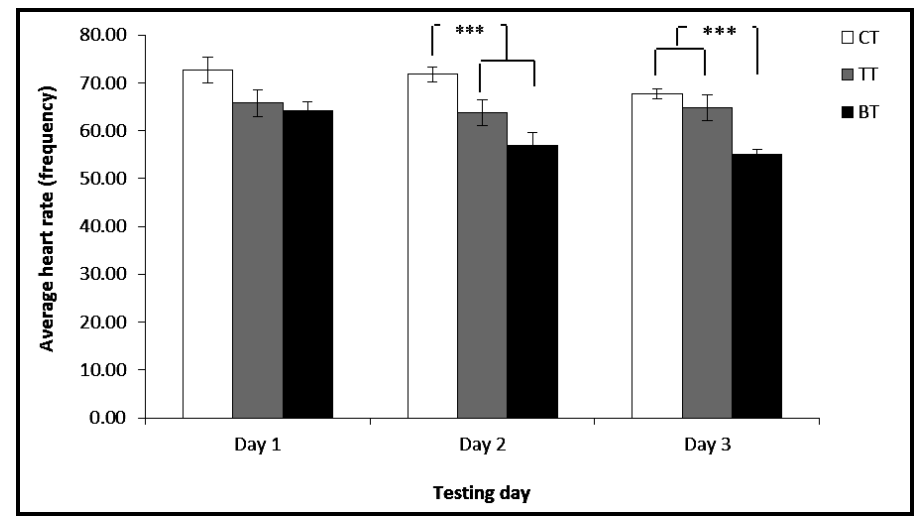

Figure 5: $\mathrm{EMM} \pm \mathrm{SE}$ 'average frequency heart rate' by the bulls in the three experimental treatments pre stress induction. $* * * \mathrm{P}<0.001$ 


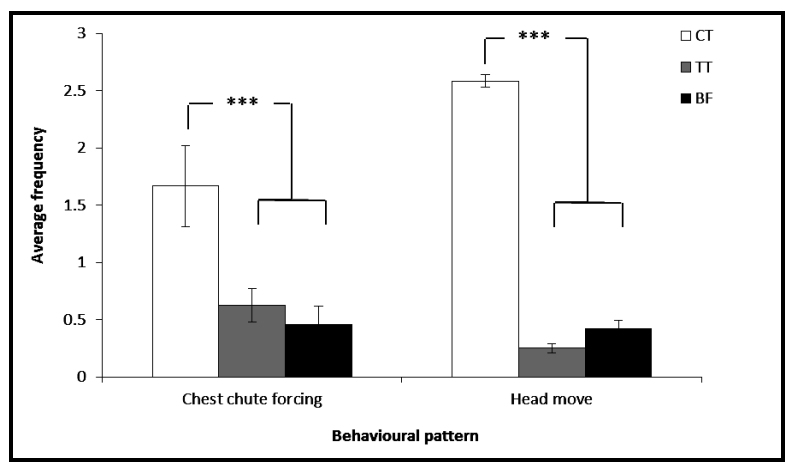

Figure 6: $\mathrm{EMM} \pm \mathrm{SE}$ 'average frequency chest chute forcing and head move' by the bulls in the three experimental treatments during stress induction. $* * * \mathrm{P}<0.001$

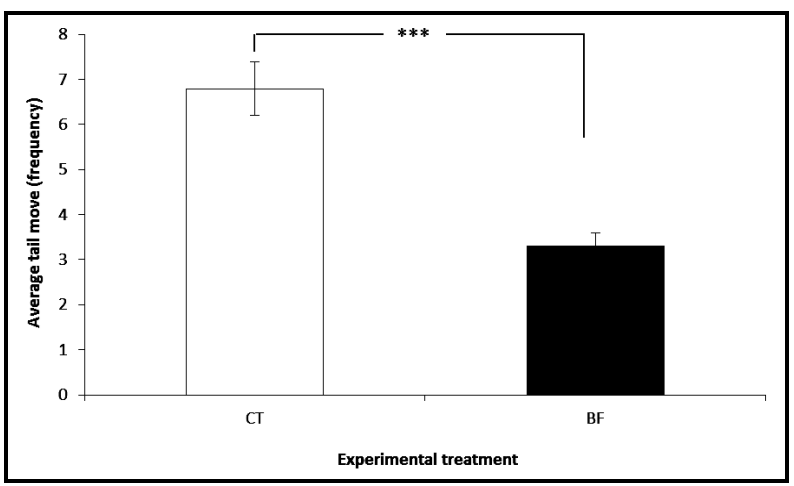

Figure 8: $\mathrm{EMM} \pm \mathrm{SE}$ 'average frequency tail move' by the bulls in the control and blindfold experimental treatments during stress induction. $* * * \mathrm{P}<0.001$

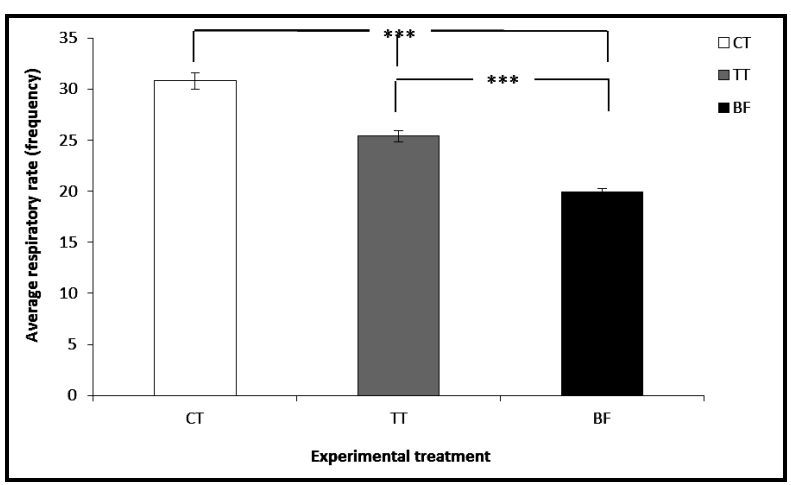

Figure 10: $\mathrm{EMM} \pm \mathrm{SE}$ 'average frequency respiratory rate' by the bulls in the three experimental treatments during stress induction. $* * * \mathrm{P}<0.001$

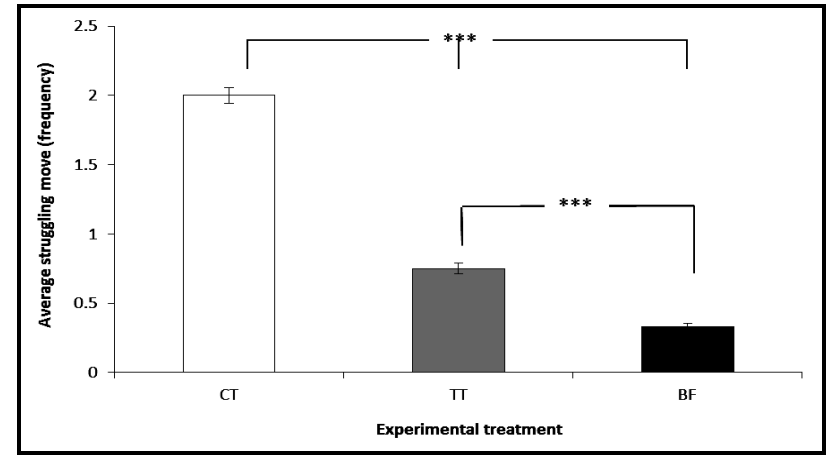

Figure 7: $\mathrm{EMM} \pm \mathrm{SE}$ 'average frequency struggling move' by the bulls in the three experimental treatments during stress induction. ${ }^{* * *} \mathrm{P}<$ 0.001

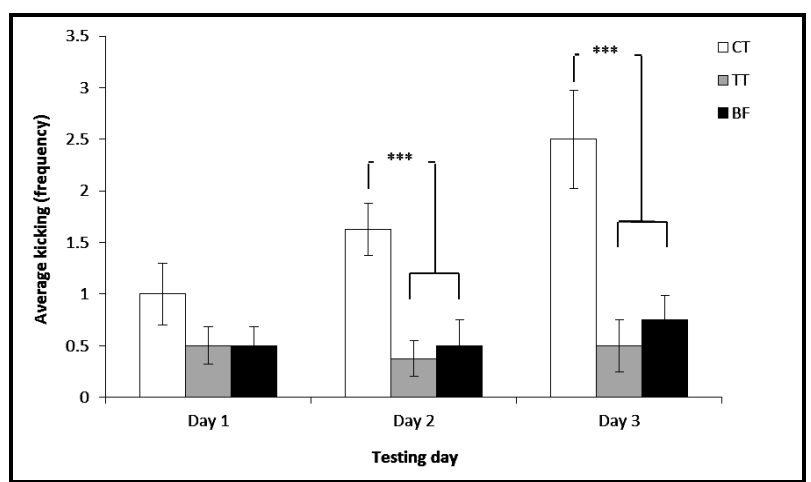

Figure 9: $\mathrm{EMM} \pm \mathrm{SE}$ 'average frequency kicking' by the bulls in the three experimental treatments during stress induction. ${ }^{* * *} \mathrm{P}<$ 0.001

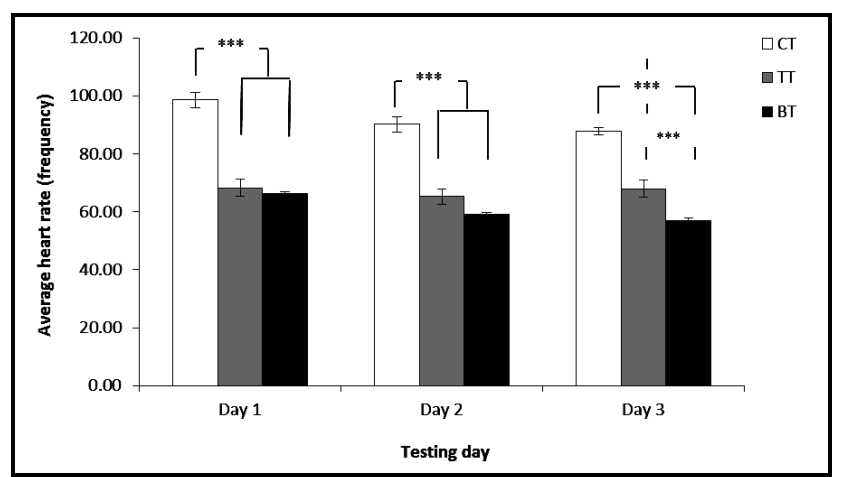

Figure 11: $\mathrm{EMM} \pm \mathrm{SE}$ 'average frequency heart rate' by the bulls in the three experimental treatments during stress induction. ${ }^{* * *} \mathrm{P}<$ 0.001 


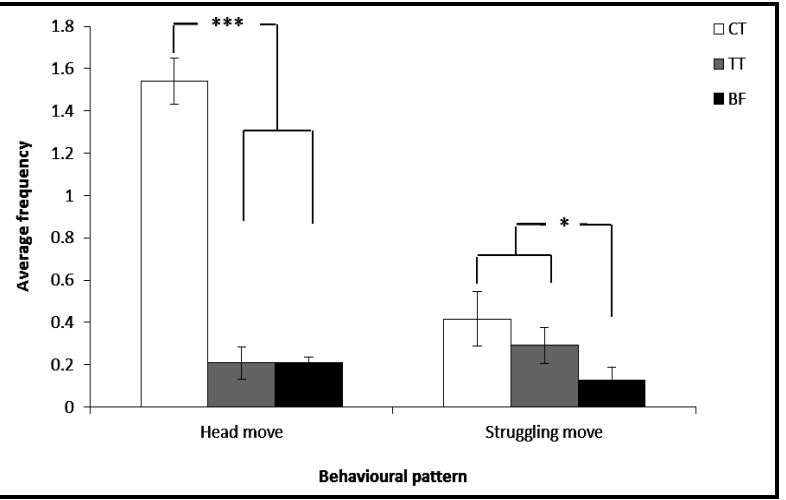

Figure 12: $\mathrm{EMM} \pm \mathrm{SE}$ 'average frequency head move and struggling move' by the bulls in the three experimental treatments post stress induction. ${ }^{*} \mathrm{P}<0.05 * * * \mathrm{P}<0.001$

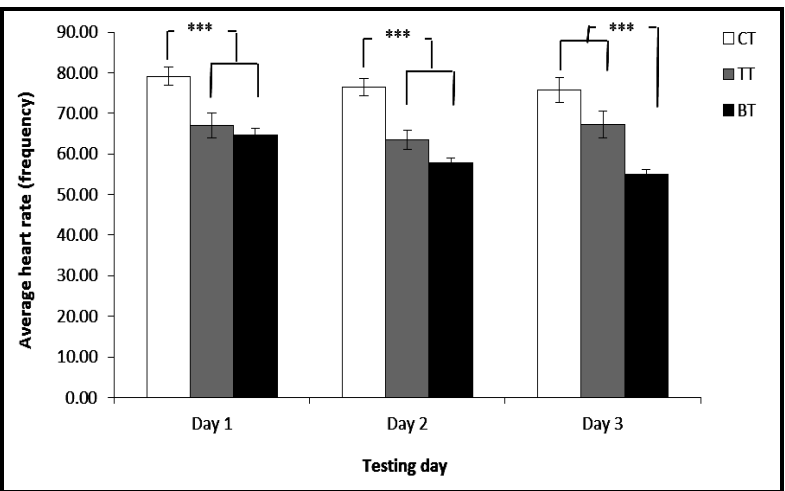

Figure 14: $E M M \pm S E$ 'average frequency heart rate' by the bulls in the three experimental treatments post stress induction. ${ }^{* * *} \mathrm{P}<0.001$

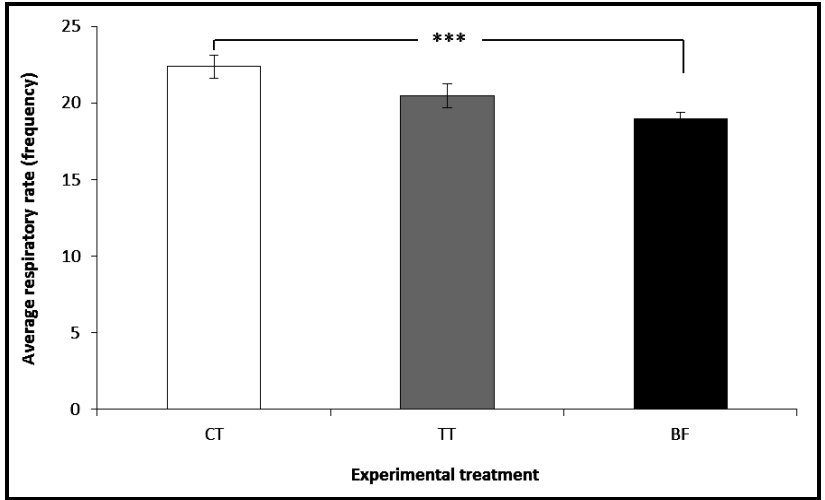

Figure 13: $\mathrm{EMM} \pm \mathrm{SE}$ 'average frequency respiratory rate' by the bulls in the three experimental treatments post stress induction. $* * * \mathrm{P}<$ 0.001

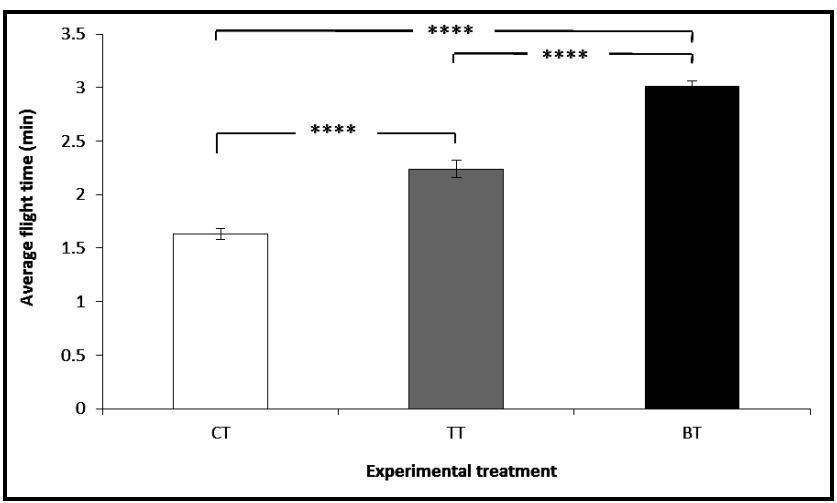

Figure 15: $\mathrm{EMM} \pm \mathrm{SE}$ 'average flight time' by the bulls in the three experimental treatments during stress induction. $* * *$ $\mathrm{P}<0.001$ 


\section{DISCUSSION}

The results of this experiment showed that both blindfolding and tail bending of Egyptian buffaloes might be beneficial in reducing behavioural and physiological stress responses during restraint for routine veterinary examination of animals. The findings of the current experiment showed that the two procedures used during the restraint (blindfold and tail bend) of animals decreased behavioural indicators of stress including chest chute forcing, head move, struggling move, and physiological indicators of stress including heart and respiratory rate, and shortened the flight time compared to control animals pre, during and post handling of the animals.

The reduction in stress responses in blindfolded buffaloes observed in the current study could be due to the reduced level of fear in these animals. Mitchell et al. (2004) reported that blindfolding beef heifers during routine invasive procedures induced a reduction of $43.39 \%$ in their behavioural (struggling and movement) and a reduction of $15.4 \%$ in their physiological (heart rate) responses to restraint. Fowler (1995) raised the possibility that blindfolding animals eliminates visual communication between animals and their environment (both animate and inanimate) and therefore renders them calmer. Similarly, Andrade et al. (2001) showed that eliminating sensory visual inputs in adult Brahman cattle during restraint through the use of musk decreased their emotional reactivity. Jones and Satterlee, (1997) demonstrated that covering the broilers' heads with a hood before they were shackled substantially reduced the time spent struggling and the numbers of struggling bouts and vocalizations.

There is also the possibility that, in the current study, blindfolded animals displayed lower levels of behavioural and physiological indicators of stress because they were more fearful. Tonic immobility, as a reaction of an animal to fear, is characterized by a catatoniclike state of reduced responsiveness to external stimulation has been documented in other species such as domestic fowl (e.g. Jones, 1986). However, this possibility can be ruled out by the findings of Dantzer et al. (1983) and Kilgour (1975) who observed that the proportion of cows that were immobile in fear provoking situations were very low.

It could also be that blindfolded buffaloes displayed lower levels of fear compared to tail bended buffaloes because of the elimination of visual inputs. Restriction of vision through the reduction of ambient light intensity has been demonstrated to make nonhuman animals calmer during restraint or capture such as domestic chicken (Jones and Satterlee, 1997; Jones et al., 1998), red deer (Pollard and Littlejohn, 1994; Haigh et al., 1995) and squirrels (Mantor et al., 2014). However, the present study could not denote whether the blindfolded buffaloes were calmer because blindfold eliminated the ability of animals to detect the presence of humans in close proximity or all visual inputs (presence of human and other environmental variables). However, bearing in mind that chickens, deer, squirrels and also buffaloes are prey species, it appears that eliminating vision in these species may impair their ability to assess the environment. It has been shown that removing distractions such as shadows, reflections and people from the visual field of livestock species facilitate their movement and stop balking and stops (Grandin and Johnson, 2005; Grandin, 2007).

On the other hand, the reduction in stress responses in blindfolded buffaloes relative to tail bended ones could be due to stress experienced by the latter during the application 
of tail bending method. Tail bending has been simply regarded as a restraining technique for controlling movement of cattle, but it has been agreed upon that it may have a calming effect on calves (Woodley, 2007). Additionally, bending tails of calves can be comparable to the twitching procedure in horses in which the tip of a horse's nose is pinched and twisted during handling. It is believed that this procedure releases endorphins and alleviates pain in horses (Lagerwaij, 1984). Therefore, there is the possibility that applying tail bending to buffaloes might have reduced their reactivity compared to control animals but might have also increased stress responses of direct and prolonged physical handling of animals compared to blindfold method. However, further studies might be needed to investigate the effects of tail bending in buffaloes including whether it induces endorphins release or it acts through different mechanisms in order to see if tail bending has the same effect as twitches in horses.

\section{CONCLUSION}

It could be concluded that, both tail bend and blindfold water buffaloes decreased behavioural and physiological indicators of stress responses but blindfold appeared more beneficial and may therefore be recommended to reduce stress accompanying routine veterinary examination, to facilitate handling ease of buffaloes and to improve their welfare. This improvement in the welfare of buffalo bulls is good from both the scientific and economic perspectives and also for the sake of public considerations. The reduction in the stress responses may also be of particular importance to affirm the safety of both the animal and the handler when restraining buffaloes for routine veterinary examination and treatment.

\section{REFERENCES}

Agnes, F., Sartorelli, P., Abdi, B.H. and Locatelli, A. (1990): Effect of transport loading or noise on blood biochemical variables in calves. American Journal of Veterinary Research, 51, 1679-1681.

Andrade, O., Orihuela, A., Solano, J. and Galina, C.S. (2001): Some effects of repeated handling and the use of a mask on stress responses in zebu cattle during restraint. Applied Animal Behaviour Science, 71, 175-181.

Baszczak, J.A., Grandin, T., Gruber, S.L., Engle, T.E., Platter, W.J., Laudert, S.B., Schroeder, A.L. and Tatum, J.D. (2006): Effects of rectopamine supplementation on behavior of British, Continental, and Brahman crossbred steers. Journal of Animal Science, 84, 3410-3414.

Boissy, A. and Bouissou, M.F. (1988): Effects of early handling on heifer's subsequent reactivity to humans and unfamiliar situations. Applied Animal Behaviour Science, 20, 259-273.

Borghese, A. (2010): Development and perspective of buffalo and buffalo market in Europe and Near East. Proceeding of the $9^{\text {th }}$ World Buffalo Congress Buenos Aires, 25-28 April. In "Revista Veterinaria" 21, 20-31.

Broom, D.M. (1988): The scientific assessment of animal welfare. Applied Animal Behaviour Science, 20, 5-19.

Broom, D.M. and Johnson, K.G. (1993): Stress and Animal Welfare. Chapman \& Hall, London, UK.

Chirase, N.K., Greene, L.W., Graham, G.D. and Avampato, J.M. (2001): 
Influence of clostridial vaccines and injection sites on performance, feeding behavior, and lesion size scores of beef steers. Journal of Animal Science, 79, 1409-1415.

Cockrill, W.R. (1974): The husbandry and health of the domestic buffalo. Food and Agriculture Organization of the United Nations, Rome.

Dantzer, R., Mormede, P., Bluthé, R.E. and Soissons, J. (1983): The effect of different housing conditions on behavioural and adrenocortical reactions in veal calves. Reproduction Nutrition Development, 23, 501-508.

Ewbank, R. (1961): The behaviour of cattle in crushes. Veterinary Record, 73, 853856.

Ewbank, R. (2000): Handling cattle in intensive systems. In: Grandin, $\mathrm{T}$. (Ed.), Livestock Handling and Transport. CABI Publishing, New York, NY, Pp. 87-102.

FAO, (2008): Food and Agricultural Organization of United Nations: Economic and Social Department: The Statistical Division. FAOSTAT (http://faostat,fao,org/default aspx).

Fisher, A.D., Crowe, M.A., Prendiville, D.J. and Enright, W.J. (1997): Indoor space allowance: Effects on growth, behaviour, adrenal and immune responses of finishing beef heifers. Animal Science, 64, 53-62.

Fowler, M.E. (1995): Tools of restraint. In: Restraint and Handling of Wild and Domestic Animals, second ed. Iowa State University Press, Ames, Iowa, Pp. 7-17.

Genther, O.N. and Hansen, S.L. (2014): Effect of dietary trace mineral supplementation and a multi-element trace mineral injection on shipping response and growth performance of beef cattle. Journal of Animal Science, 92, 2522-2530.

Grandin, T. (1998): Handling methods and facilities to reduce stress on cattle. Veterinary Clinics of North America, Food Animal Practice, 14, 325-341.

Grandin, T. (2007): Behavioral principles of handling cattle and other grazing animals under extensive conditions. In: Livestock Handling and Transport. $3^{\text {rd }}$ Ed. T. Grandin, (Ed). P. 44-64 CABI International, Wallingford, UK.

Grandin, T. and Johnson, C. (2005): Animals in Translation. Scribner, New York, NY.

Grignard, L., Boivin, X., Boissy, A. and Le Neindre, P. (2001): Do beef cattle react consistently to different handling situations? Applied Animal Behaviour Science, 71, 263-276.

Haigh, J.C. and Friesen, R.W. (1995): A handling system for white-tailed deer (Odocoileus virginianus). Journal of Zoo and Wildlife Medicine, 26, 321326.

Herskin, M.S., Munksgaard, L. and Andersen, J.B. (2007): Effects of social isolation and restraint on adrenocortical responses and hypoalgesia in loose-housed dairy cows. Journal of Animal Science, 85, 240-247.

Hussein, F.M., Noseir, W.M. and ELBawab, E.I. (1997): Reproductive performance of buffaloes under some stress factors. Pp 928-932 in Proc. $5^{\text {th }}$ World Buffalo Congr., Caserta, Italy.

Jarvis, A.M., Messer, C.D.A. and Cockram, M.S. (1996): Handling, bruising and 
dehydration at the time of slaughter. Animal Welfare, 5, 259-270.

Jezierski, T., Jaworski, Z. and Górecka, A. (1999): Effects of handling on behaviour and heart rate in Konik horses: comparison of stable and forest reared youngstock. Applied Animal Behaviour Science, 62, 1-11.

Johensen, P.F., Johannesson, T. and Sandøe, P. (2001): Assessment of farm animal welfare at herd level: many goals, many methods. Acta Agricultrae Scandinavica, Section A Animal Science, 30, 26-33.

Jones, R.B. (1986): The tonic immobility reaction of the domestic fowl: a review. World Poultry Science Journal, 42, 82-96.

Jones, R.B., Hagedorn, T.K. and Satterlee, D.G. (1998): Adoption of immobility by shackled broiler chickens: effects of light intensity and diverse hooding devices. Applied Animal Behaviour Science, 55, 327-335.

Jones, R.B. and Satterlee, D.G. (1997): Restricted visual input reduces struggle in shackled broiler chickens. Applied Animal Behaviour Science, 52, 109117.

Kanchev, L.N., Danev, A., Alexandrov, K. and Deianova, P. (1997): Influence of melatonin on cortisol concentration during transport stress in buffalo. Pp 933-936 in Proc. $5^{\text {th }}$ World Buffalo Congress, Caserta, Italy.

Kegley, E.B., Spears, J.W. and Brown Jr, T.T. (1997): Effect of shipping and chromium supplementation on performance, immune response, and disease resistance of steers. Journal of Animal Science, 75, 1956-1964.
Kilgour, R. (1975): The open field test as an assessment of the temperament of dairy cows. Animal Behaviour, 23, 615-624.

Kilgour, R.J., Melville, G.J. and Greenwood, P.L. (2006): Individual differences in the reaction of beef cattle to situations involving social isolation, close proximity of humans, restraint and novelty. Applied Animal Behaviour Science, 99, 21-40.

Lagerwaij, E. (1984): The twitch in horses: a variant in acupuncture. Science, 225, 1172-1174.

Lay, D.C., Friend, T.H., Randel, R.D., Bowers, C.L., Grissom, K.K. and Jenkins, O.C. (1992): Behavioural and physiological effects of freeze or hot iron branding on crossbred cattle. Journal of Animal Science, 70, 330336.

Le Neindre, P. (1993): Evaluating housing systems for veal calves. Journal of Animal Science, 71, 1345-1354.

Mantor, M., Krause, S. and Hart, L.A. (2014): Trapping and handling squirrels: Trap modification and handling restraint to minimize injuries and stress. Wildlife Society Bulletin, 38, 152-159.

Maton, A. and Daelemans, J. (1989): Modern housing of cattle and their welfare. In: Agricultural Engineering (Vol. 2). Proc. $11^{\text {th }}$ Int. Congr. on Agricultural Engineering, Dublin, Ireland. Pp 921-925.

Mitchell, K.D., Stookey, J.M., Laturnas, D.K., Watts, J.M., Haley, D.B. and Huyde. T. (2004): The effects of blindfolding on behavior and heart rate in beef cattle during restraint. Applied Animal Behaviour Science, 85, 233 245. 
Müller, R., Schwartzkopf-Genswein, K.S., Shah, M.A. and von Keyserlingk, M.A.G. (2008): Effect of neck injection and handler visibility on behavioral reactivity of beef steers. Journal of Animal Science, 86, 12151222.

Phillips, C.J. and Santurtun, E. (2013): The welfare of livestock transported by ship. Veterinary Journal, 196, 309-314.

Pilz, M., Fischer-Tenhagen, C., Grau, M. and Heuwieser, W. (2014): Behavioural and physiological assessment of stress reactions during vaginal examination in dairy cows. Tierärztl Prax G. N. 42, 88-94.

Pollard, J.C. and Littlejohn, R.P. (1994): Behavioural effects of light conditions on red deer in a holding pen. Applied Animal Behaviour Science, 41, 127134.

Schmied, C., Waiblinger, S., Scharl, T., Leisch, F. and Boivin, $X$. (2008): Stroking of different body regions by a human: Effects on behaviour and heart rate of dairy cows. Applied Animal Behaviour Science, 109, 25-38.

Schwatzkopf-Genswein, K.S., Stookey, J.M., Crowe, T.G. and Genswein, B.M. (1998): Comparison of image analysis, exertion force, and behavior measurements for use in the assessment of beef cattle responses to hot-iron and freeze branding. Journal of Animal Science, 76, 972-979.

Schwatzkopf-Genswein, K.S., Stookey, J.M. and Welford, R. (1997): Behavior of cattle during hot-iron and freeze branding and the effects on subsequent handling ease. Journal of Animal Science, 75, 2064-2072.
Shahin, A.S.A.H. (2004): Adoption of Innovations in Smallholder Buffalo Dairy Farms in the Menoufia Province in Egypt. Ph.D. Dissertation, Berlin, University.

Solano, J., Galindo, F., Orihuela, A. and Galina, C.S. (2004): The effect of social rank on the physiological response during repeated stressful handling in Zebu cattle (Bos indicus). Physiology and Behavior, 82, 679-83.

Stewart, M., Shepherd H.M., Webster J.R., Waas J.R., McLeay L.M. and Schütz K.E. (2013): Effect of previous handling experiences on responses of dairy calves to routine husbandry procedures. Animal, 7, 828-833.

Szenci, O., Karen, A., Bajesy, A.C., Gáspárdy, A., de Sousa, N.M. and Beckers, J.F. (2011): Effect of restraint stress on plasma concentrations of cortisol, progesterone and pregnancy associatedglycoprotein-1 in pregnant heifers during late embryonic development. Theriogenology, 76, 1380-1385.

Van De Water, G., Heylen, T., Swinnen, K. and Geers, R. (2003): The impact of vertical vibrations on the welfare of calves. Dtsch Tierarztl Wochenschr Journal, 110, 111-114.

Woodley, W. (2007): Personal Communication. Cow-calf operator/owner in Northeast Texas.

Zavy, M.T., Juniewicz, P.E. Phillips, W.A. and Von Tungeln, D.L. (1992): Effects of initial restraint, weaning, and transport stress on baseline and ACTH stimulated cortisol responses in beef calves of different genotypes. American Journal of Veterinary Research, 53, 551. 


\section{الملخص العربي \\ تأثيرات عصب العينين وحني الذيل في الجاموس المصري علي رد فعله السلوكي واستجابته الفسيولوجية لإحداث الإي الموس الميري}

راضي علي محمدل، أسامة أحمد ابو إسماعيل"، مصطفي شكري" ، احمد مرسي المسلماني"و محمد عبد المجيد كامل ***"

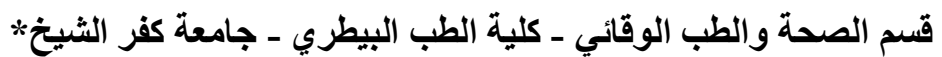

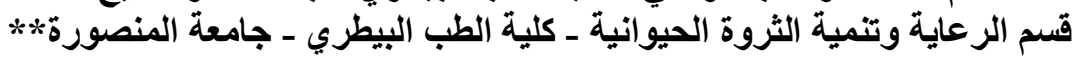

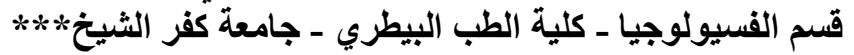

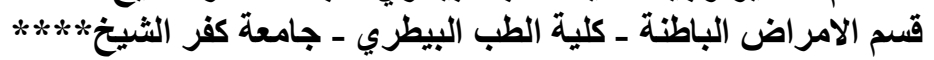

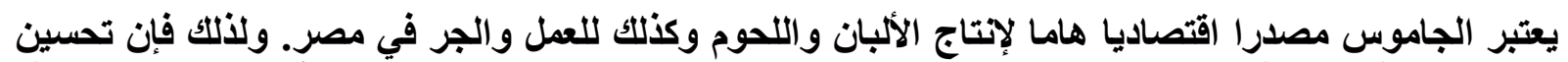

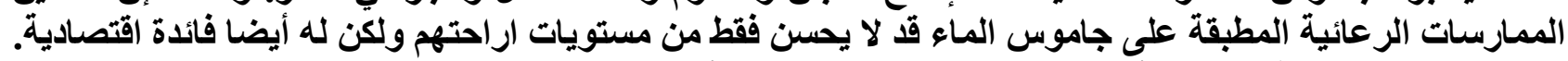

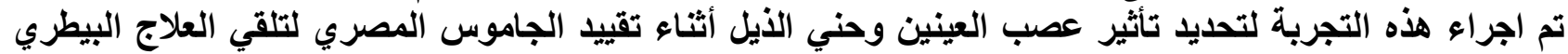

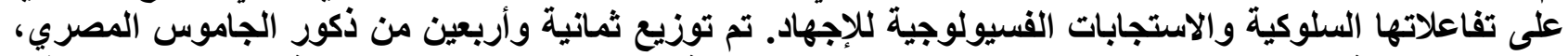

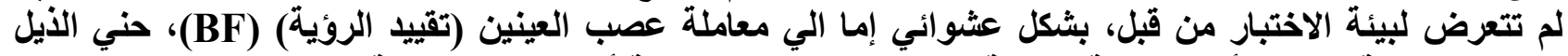

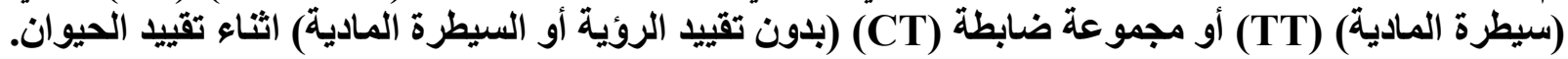

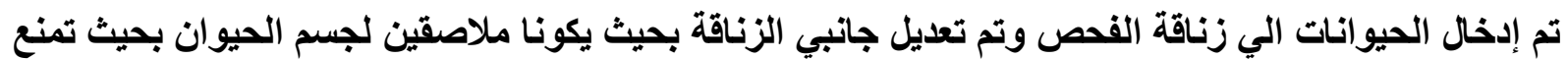

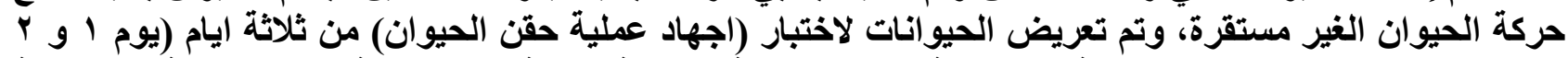

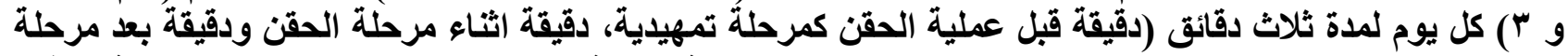

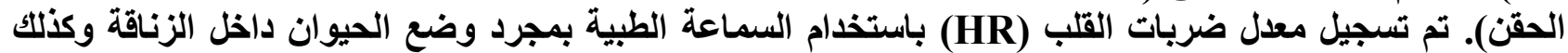
معدل التفس (RR) من خلال عد حركة منطقة الخاصرة، وتم تجميع مختلف سلوكيات رد فعل الحيوان في ورقة

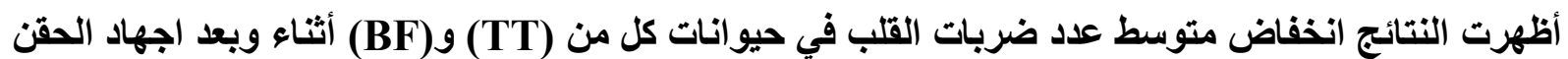

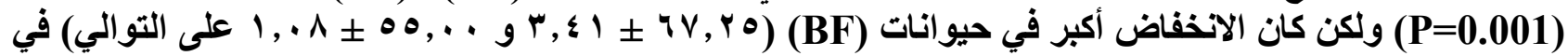

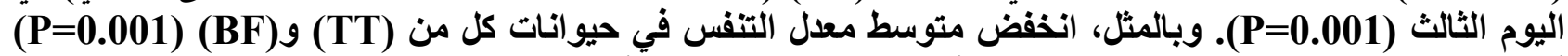

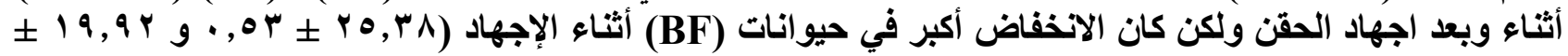
بار, · على التوالي).

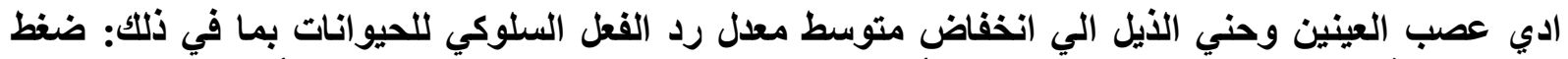

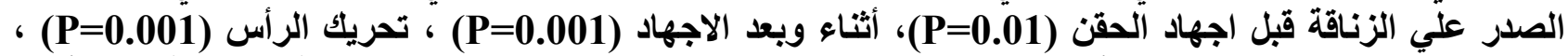

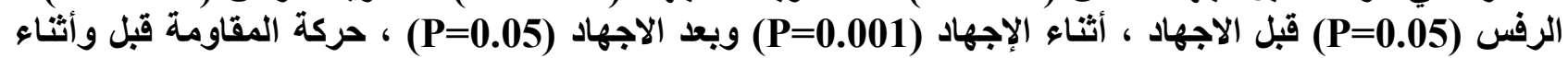

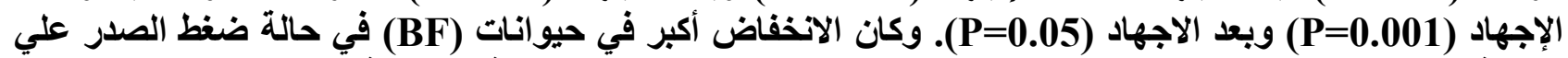

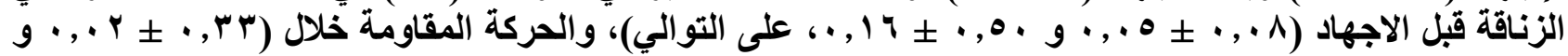

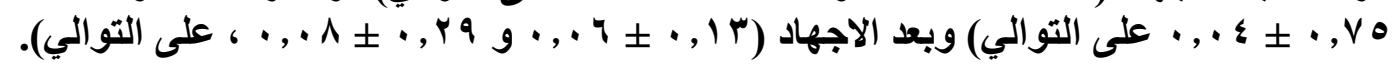

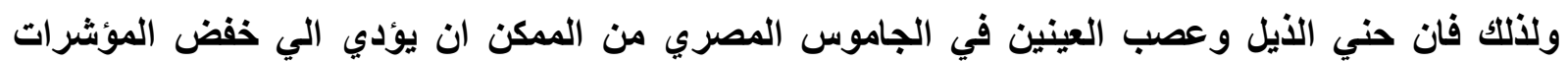

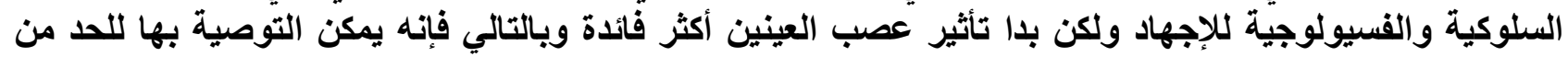
الاجهاد المصاحب للفحص البيطري الروتيني للجاموس. لإسبر 